\title{
Ciudadanía, sociedad civil y participación en políticas públicas. La experiencia de los Foros Vecinales de Seguridad en el municipio de La Plata
}

\section{Julio Sarmiento}

Facultad de Trabajo Social de la Universidad Nacional de La Plata, Argentina

\section{Claudia Tello}

Facultad de Trabajo Social de la Universidad Nacional de La Plata, Argentina

\section{Ramiro Segura}

Facultad de Trabajo Social de la Universidad Nacional de La Plata, Argentina

Ciudadanía, sociedad civil y participación en políticas públicas. La experiencia de los Foros Vecinales de Seguridad en el municipio de La Plata

Resumen: El artículo presenta resultados de una investigación sobre la participación ciudadana en políticas de seguridad, desarrollada en el municipio de La Plata, Buenos Aires, Argentina ${ }^{1}$. El trabajo se centra en el análisis de las prácticas de participación observadas en los foros vecinales de seguridad y en la significación que los foristas le asignan a las mismas. Cabe aclarar que para el desarrollo de la investigación se recurrió a técnicas cualitativas de recolección y análisis de datos, como la observación participante, entrevistas a informantes clave y entrevistas a foristas. Una conclusión importante a la que se arriba es que la participación no aprovecha todas las posibilidades de la política pública, en tanto en los foros se expresa una 'ciudadanía limitada'. Un ejemplo de ello es la autoidentificación de los foristas como ‘vecinos', una categoría más bien despolitizada y moral. Finalmente, se espera que el artículo pueda convertirse en un aporte, desde un estudio empírico, al debate sobre la significación política de la participación de la sociedad civil en políticas públicas Palabras clave: políticas de seguridad pública, participación, ciudadanía.

Cidadania, sociedade civil e participação em políticas públicas. A experiência dos Foros Vecinales de Seguridad no município de La Plata

Resumo: O artigo apresenta os resultados de uma pesquisa sobre a participação cidadã em políticas de segurança, desenvolvida no município de La Plata, Buenos Aires, Argentina. O trabalho concentra-se na análise das práticas de participação observadas nos foros vecinales de seguridad e na significação dada pelos integrantes dos fóruns a estas práticas. Cabe esclarecer que, para o desenvolvimento da pesquisa, recorreu-se a técnicas qualitativas de coleta e análise de dados, tais como a observação participante, entrevistas a informantes-chave e entrevistas a integrantes dos fóruns. Uma conclusão importante desta pesquisa refere-se à participação não valer-se de todas as possibilidades da política pública, de modo que expressa nos fóruns uma 'cidadania limitada'. Um exemplo disso é a auto-identificação dos integrantes dos fóruns como 'vizinhos', uma categoria, por assim dizer, despolitizada e moral. Finalmente, espera-se que o artigo possa representar uma contribuição, como estudo empírico, ao debate sobre a significação política da participação a sociedade civil nas políticas públicas.

Palavras-chave: políticas de segurança pública, participação, cidadania.

\section{Citizenship, Civil Society and Participation in Public Policies. The Experience of the Community} Safety Forums in the Municipality of La Plata

Abstract: The article presents results of a study about citizen participation in public safety policies in the municipality of La Plata, Buenos Aires, Argentina. The work focuses on the analysis of the participation practices observed in Community Safety Forums and on the meaning that the forum members attribute to these forums. The study utilized qualitative data collection and analysis techniques, such as participant observation, interviews with key informants and interviews with Forum members. One important conclusion is that the participation does not take advantage of all the public policy possibilities, and that the forums thus express a form of "limited citizenship". An example of this is the self-identification of the forum members as 'neighbors', a category that can be seen as moral and depoliticized. Finally, it is hoped that the article can support empiric research and the debate about the political meaning of participation of civil society in public policies.

Key words: public safety policies, participation, citizenship. 


\section{El debate sobre la participación en políticas públicas ¿Autorregulación o más democracia?}

Durante la última década se han multiplicado las experiencias de políticas públicas que recurren a la participación de la sociedad civil como uno de sus rasgos distintivos. A su vez, y aguijoneado por esas experiencias, se ha encendido un interesante debate político-académico sobre la significación política última de esta nueva orientación de las políticas públicas.

Si se graficara esta discusión de manera espacial, podría sostenerse que es posible visualizar dos polos bien diferenciados respecto del sentido político de la participación de la sociedad civil con algunas posiciones intermedias también significativas.

En efecto, en el debate es posible distinguir aquellos que entienden que la apelación a la participación de la sociedad civil en las políticas públicas es un componente más del ideario neoliberal. Desde esta posición, se argumenta que el neoliberalismo ha promovido una vuelta al Estado 'mínimo', por una parte, $y$, por la otra, ha otorgado centralidad al mercado 'autorregulado' como espacio privilegiado para orientar el desarrollo y para la provisión de bienes colectivos significativos para el bienestar, que anteriormente eran provistos de manera universal mediante la oferta estatal.

En ese marco, la apelación a la participación operaría como una especie de resumidero al que va a parar todo lo que no 'debe' tratar de manera directa el Estado y sus agencias, y todo lo que no puede ser procesado por el mercado. Un buen ejemplo, en ese sentido, lo constituye - para los que defienden esta lectura sobre la participación - las políticas sociales dirigidas a los pobres. Aquí, la interpretación es que, detrás de la apelación a la participación de los beneficiarios en la política social, se encuentra la idea de que el Estado no puede - por la escasez de recursos - y no debe - por su carácter ineficiente - atender las necesidades de los sectores pobres, salvo en situaciones especiales caracterizadas por el riesgo y que constituyan una amenaza a la subsistencia de esos grupos sociales. Más bien serían los pobres los que deben procurarse los medios para asegurarse sus necesidades. El Estado sólo debe acompañar y fortalecer, mediante la política social, las iniciativas que provengan de ese sector. Así, la participación sólo sería un instrumento posible de la autorregulación social o un mecanismo a través del cual operaria la desresponsabilización social del Estado y no una herramienta de los pobres para discutir una distribución diferente de la riqueza, el poder o de los bienes sociales administrados por el Estado.

En el polo opuesto se ubican quienes defienden activamente la participación de la sociedad civil en materia de políticas públicas, como una manera de promover la democratización del Estado y el fortalecimiento de la ciudadanía. Para los que sostienen esta posición, la participación de la sociedad civil en políticas públicas no ha sido una graciosa concesión del Estado, sino una conquista de los movimientos sociales y un resultado del 'despertar de la sociedad civil' que reclama, a través de las organizaciones que se ha dado, un lugar en la toma de decisiones que hacen al futuro común de una sociedad. Así, se habría operado un ensanchamiento de la esfera pública con la emergencia de nuevos actores 'legítimos' movimientos y organizaciones sociales - y enriquecido la agenda pública con nuevas demandas y perspectivas de abordaje de los temas públicos.

Para los defensores de esta mirada, la participación de la sociedad civil introduce un cambio cualitativo en la democracia al promover, de la mano del fortalecimiento de la ciudadanía, el pasaje de una democracia representativa a una crecientemente participativa.

Entre esos polos opuestos se ubican quienes entienden - y defienden - la participación como un medio para movilizar recursos que anidan en la sociedad civil - capacidades organizacionales, saberes - y de ese modo alcanzar los objetivos de la política pública, además de observar en la participación un medio para tonificar a la misma con una mayor legitimidad. En este caso, los ejemplos pueden ser las propuestas para el desarrollo local participativo o las tendientes a fortalecer y recuperar para la política pública el capital social de una comunidad.

También en una posición intermedia es posible encontrar a quienes cuestionan la apelación a la participación de la sociedad civil, en tanto ésta ha ido acompañada en muchos casos, y en especial en América Latina, de prácticas clientelares o de cooptación, por parte del Estado, de actores sociales, en un marco de profundas desigualdades y de escasez de recursos para sostener la movilización social o política. Para los que acuerdan con esta visión, se han puesto en marcha, en nombre de la participación de los beneficiarios, en especial en el marco de las políticas sociales, redes oficiales de asistencia que utilizan a las organizaciones comunitarias para inyectar unos pocos recursos que garanticen el control del conflicto social y aseguren la movilización dependiente de los pobres.

Como puede observarse, no hay una posición unívoca respecto de la evaluación de la participación de la sociedad civil en políticas públicas. Presentándose en ocasiones un debate demasiado ideologizado, con posiciones apriorísticas, que no contribuye a echar luz sobre las experiencias concretas de participación ${ }^{2}$.

Justamente, parte de la intención de nuestro trabajo de investigación es indagar sobre los alcances y limitaciones, restricciones y potencialidades de la participación de la sociedad civil en una política pú- 
blica concreta: los foros de seguridad de la provincia de Buenos Aires. ${ }^{3}$

\section{Metodología}

Los estudios empíricos sobre la participación se han centrado básicamente en dos aspectos. Por un lado, la estructura de oportunidades que brinda el sistema político, el Estado o sus agencias, observando los dispositivos institucionales, las prácticas efectivas $\mathrm{u}$ orientaciones valorativas respecto de la participación de la clase política o los ejecutores de políticas públicas. Por otro lado, se ha prestado atención a las prácticas, valores, representaciones, de quienes participan, entendiendo que este aspecto es fundamental para comprender buena parte de la práctica concreta de la participación.

Si bien nuestra investigación incluye el estudio de ambos aspectos - es decir, la formulación, diseño e implementación de la política de los foros de seguridad, así como también las prácticas y las significaciones asignadas por los foristas a la participación - en este artículo nos detenemos en la última cuestión mencionada.

Cabe aclarar que nuestra labor se restringe a los foros operantes en el ámbito del municipio de La Plata y que el material empírico sobre el que se trabajó ha sido resultado de observaciones, entrevistas a informantes clave y entrevistas a foristas.

En la actualidad, de los quince foros vecinales que deberían funcionar en el municipio de La Plata sólo se encuentran activos diez. Las entrevistas se realizaron en siete de los foros. En cada uno de ellos se hicieron entrevistas en profundidad a foristas. La muestra se seleccionó teniendo en cuenta dos criterios. Un criterio fue la ubicación geográfica de los foros, distinguiendo entre aquellos que pertenecen al casco urbano de la ciudad y los ubicados en la periferia urbana. El otro criterio fue el estilo de liderazgo presente en cada foro, identificando foros personalistas y colegiados. Mientras el primer criterio estuvo presente desde el inicio de la investigación, el segundo fue adoptado luego de entrevistas realizadas a informantes clave de la Subsecretaría de Participación Comunitaria. Los ejes de las entrevistas a los foristas fueron básicamente tres: a) una reconstrucción del proceso de formación del foro y de las principales acciones desplegadas; b) la significación dada a la participación; c) las representaciones de la seguridad, la inseguridad y la violencia.

Las observaciones se hicieron en cuatro de los foros analizados, ubicados uno en el casco urbano y tres en barrios periféricos. En todos los casos se hicieron anotaciones de campo y se grabaron las reuniones con consentimiento de los foristas. En tres de los foros, se observó el proceso de elaboración del mapa vecinal de prevención del delito. Asimismo, se observaron reuniones internas de los foros, de los foros con personal del Ministerio de Seguridad encargado del Programa y/o con Jefes Policiales de las comisarías respectivas.

Se realizaron entrevistas a informantes clave, como fue expresado arriba, de la Subsecretaría de Participación Comunitaria, con el fin de relevar información para la selección de los casos a estudiar, y también se incluyeron cuestiones referidas al diseño e implementación de la política de participación comunitaria en los foros de seguridad.

Para el análisis de las representaciones vinculadas a los conceptos de Participación, Seguridad, Inseguridad, Violencia y términos relacionados, se aplicaron sobre los textos resultantes de la desgrabación de entrevistas las operaciones analíticas que propone la Semiótica de Enunciados de Magariños de Morentin (1996), metodología ya aplicada en otras investigaciones, y se contrastó con los datos construidos a partir de las observaciones. Se sistematizaron los diferentes tipos de acciones emprendidas por los foros, encontrándonos en la actualidad tratando de crear una tipología que nos sirva para profundizar el análisis. De lo expuesto, se desprende que el presente artículo sólo recoge algunos avances de una investigación en curso.

Por último, debemos señalar que los procedimientos desplegados a lo largo de la investigación respetaron los principios éticos de la declaración de Helsinki, contándose con el consentimiento informado de los actores sociales con quienes desarrollamos el trabajo, una vez que fueron explicitados las finalidades y los métodos de la investigación. Adicionalmente, aplicando principios éticos con vistas a asegurar el anonimato de nuestros informantes, en este artículo no se dan nombres propios de los informantes ni referencias espaciales o institucionales muy precisas que podrían identificarlos.

\section{La institucionalización de la participación en la política de seguridad de la provincia de Buenos Aires: los foros y los programas ministeriales sustentados en la participación comunitaria}

En el año 1997, en el marco de una fuerte crisis de seguridad, el entonces gobernador Eduardo Duhalde decide la intervención civil de la Policía de la Provincia de Buenos Aires.

En paralelo a la intervención, funcionará el Instituto de Política Criminal, que bajo la dirección del Dr. Carlos Arslanián cobijará la labor de un conjunto de especialistas que tendrá por objetivo proponer una reforma integral ${ }^{4}$ de la política de seguridad de la 
provincia. El trabajo de estos expertos cristaliza, no sin modificaciones introducidas por los poderes Ejecutivo y Legislativo, en la sanción de las leyes de Seguridad Publica (12.154) y de Organización de las Policías de la Provincia de Buenos Aires (12.155) ${ }^{5}$, en el año 1998.

La última de estas leyes desarticula definitivamente la anterior Policía Bonaerense, al generar una fuerte descentralización - vía la creación de jefaturas departamentales que coinciden con los departamentos judiciales - y una diferenciación funcional entre distintas policías: de seguridad, de investigaciones y vial.

A su vez, la Ley de Seguridad Pública introducía una innovación significativa: la participación comunitaria en la política de seguridad. Es más, se creaba una nueva institucionalidad para la participación, reconocida expresamente por la ley: los foros de seguridad.

La reforma del sistema de seguridad de la provincia se da en un contexto en el que miembros de las fuerzas de seguridad provincial aparecían implicados en la comisión de delitos de importante trascendencia pública. Ello tras décadas de autonomía y autogobierno de la Policía Bonaerense, en las cuales la seguridad era definida sólo como una cuestión meramente policial y la respuesta dominante frente al incremento del delito era únicamente punitiva, sea por mayor represión, por más presencia policial en las calles o por endurecimiento del código penal ${ }^{6}$.

Pero a su vez, la reforma se da en un marco de fuerte discusión sobre los sistemas de seguridad en diversos lugares del mundo. De hecho, al momento de la reforma coexistían claramente, al menos, dos paradigmas sobre la seguridad pública: de un lado estaban quienes propiciaban la tolerancia cero y el reforzamiento punitivo del estado como estrategia central de control sobre el delito, enfatizando que el mantenimiento del orden público debía ser el principio orientador del accionar de las fuerzas de seguridad; del otro lado, se ubicaban quienes sostenían que los derechos humanos no debían ser un límite del accionar policial, sino el norte que guiara su accionar, por lo que se propiciaba el abandono de la noción de orden público. Asimismo, desde esta última posición, se sostenía la importancia central de la prevención social y situacional del delito, como forma de reducir las condiciones sociales que lo posibilitaban y las estructuras de oportunidad que lo propiciaban. Es en este contexto donde hay que ubicar, por ejemplo, el despliegue de las experiencias de la 'policía de proximidad' y otras experiencias en diferentes lugares del mundo vinculadas con la prevención ${ }^{7}$.

La reforma intenta justamente poner fin a la autonomía y autogobierno de las fuerzas de seguridad provincial y pensar a la seguridad pública como algo más que una preocupación sólo policial. Por ello, la Ley de Seguridad Pública implicó - frente al modelo tradicional - un cambio sustantivo de concepción.

Según la Ley, tres son los tipos de foros: vecinales - que coinciden con el ámbito de actuación de cada comisaría; municipales - que nuclean a los foros vecinales que operan en el territorio de cada municipio de la provincia; y, finalmente, departamentales cuya incumbencia coincide con la jefatura departamental policial respectiva.

Si bien cada uno de estos tipos de foros tiene funciones y misiones diferenciadas, en términos generales lo que se busca desde la normativa vigente es la cogestión de la política de seguridad de la provincia entre Estado - sociedad civil y el control de gestión externo. ${ }^{8}$

Inicialmente, la reforma no alivió de manera inmediata el problema de la seguridad en la provincia. A su vez, cambios en la gestión gubernamental no le otorgaron continuidad a la nueva política y hasta se pusieron en marcha orientaciones de políticas contrarias al espíritu de la Ley de Seguridad, como por ejemplo durante la gestión de Aldo Rico al frente del Ministerio de Seguridad provincial.

En el año 2003, y en el marco de una nueva crisis de seguridad, el Dr. Carlos Arslanián asumió nuevamente como Ministro de Seguridad ${ }^{9}$. Así, volvieron a la gestión funcionarios que habían impulsado e implementado la aplicación de la reforma. Con ellos cobró una nueva dinámica la participación comunitaria en la política de seguridad.

La gestión actual del Ministerio impulsa la participación comunitaria básicamente con la intención de actuar sobre dos ejes fundamentales: el control de gestión del servicio policial y la prevención social y situacional del delito. Esos ejes se implementan a través de dos programas: el Programa de Control y Evaluación de Respuesta, Calidad y Actitud del servicio policial (Programa CERCA) y el Programa de Respuestas Múltiples (PRM).

El primero de los programas tiene por objetivos que los foros puedan: enriquecer el diagnóstico de seguridad local; planificar acciones de prevención; realizar acciones de monitoreo y control del servicio policial; implementar un sistema de evaluación del 
servicio policial; realizar propuestas de mejoramiento del servicio policial.

Un componente significativo del Programa CERCA es la realización del mapa de prevención del delito. Este es un instrumento por el cual, y a través de una metodología participativa, el foro identifica tanto conflictos sociales como características físicas del barrio (falta de iluminación, terrenos baldíos descuidados, la falta de accesibilidad a los barrios, etc.) que puedan convertirse en condiciones propicias para la comisión de delitos. Luego, se acuerdan estrategias para su resolución, entre el foro, el Ministerio de Seguridad (2004), las autoridades policiales y otros actores, como el municipio respectivo y, en ocasiones, empresas de servicios públicos. Estos acuerdos quedan expresados en un acta compromiso que se evalúa periódicamente con el objeto de seguir su cumplimiento.

Por su parte, el Programa de Respuestas Múltiples identifica y moviliza recursos estatales del área de política social, con el fin de propiciar la intervención de organizaciones comunitarias que tienen por objetivo actuar sobre la prevención del delito a través de la promoción del desarrollo y la integración social, en especial de jóvenes y de adolescentes.

\section{Los foros vecinales en el municipio de La Plata: una breve descripción sociológica}

Según la Ley de Seguridad, es el Intendente de cada municipio quien, a través de algun área del gobierno local, convoca en la jurisdicción de cada comisaría a la conformación de los foros. También según la ley, los foros deben ser constituidos por representantes de instituciones y organizaciones comunitarias con cierta trayectoria de trabajo en el territorio y que se encuentren interesadas en los temas asociados a la seguridad pública.

En el caso de La Plata, y según se desprende de nuestro relevamiento, éste no ha sido el proceso de conformación de la mayoría de los foros. Por el contrario, es posible observar una gran diversidad en las modalidades de convocatoria y conformación de los foros.

Así, hemos detectado foros que se constituyeron en respuesta a la iniciativa de vecinos - no nucleados necesariamente en organizaciones comunitarias que, preocupados por la situación de "inseguridad" en sus barrios y en búsqueda de soluciones, se toparon con esa institucionalidad y decidieron movilizar a las organizaciones comunitarias para la conformación de los foros.

En otras ocasiones, vecinos que de alguna forma venían trabajando en temas asociados a la seguridad - como por ejemplo, violencia familiar - conocieron los alcances de la Ley e impulsaron la constitución del foro en su ámbito barrial.
En uno de los casos, la convocatoria a la constitución fue iniciativa de un dirigente político barrial que respondía al gobierno local, pero que en el proceso de constitución y organización definitiva fue - no sin conflicto - desplazado por las organizaciones que respondieron a la convocatoria, en nombre de la autonomía del foro.

A su vez, la gestión actual del Ministerio de Seguridad ha impulsado la convocatoria a la constitución de algunos foros en aquellas jurisdicciones de comisarías que no lo tenían. En estos casos, la mecánica ha sido generalmente la de organizar reuniones con instituciones vecinales, dar a conocer la Ley de Seguridad Pública y propiciar la creación del foro con las organizaciones que responden a la convocatoria y se muestran interesadas en el tema.

De la descripción realizada se desprende que no hay una matriz común en el proceso de constitución de los foros en el ámbito territorial donde realizamos nuestra investigación, aunque sí existe un rasgo compartido por casi todos los casos que es la búsqueda de autonomía respecto del poder local y del Ministerio desde el inicio mismo de la organización foral. Es decir, los foros se presentan a si mismos, con independencia del modo de convocatoria, como espacios autónomos desde su más temprana organización.

Incluso esa autonomía se ha visto reflejada en el impulso de un espacio propio de los foros y foristas, el interforo, en momentos en que la gestión del Ministerio - por ejemplo bajo la conducción de Aldo Rico - prácticamente desconoció a los foros como espacios para la cogestión de la seguridad pública y en que, al decir de un forista de Villa Elvira, la creación de ese espacio fue "...un intento de los foros de resguardar y apropiarse el espíritu de la Ley de Seguridad Pública y mantener la vigencia de la participación comunitaria". En la actualidad, ese espacio está siendo revivificado como un ámbito donde tratar temas y problemas asociados al funcionamiento de los foros, además de compartir experiencias y dotar de mayor poder de negociación a los foros, respecto de la autoridad ministerial o respecto de las instancias policiales, como por ejemplo la Jefatura Departamental de la policía a la que pertenece el municipio de La Plata.

Así como no hay una matriz común en el proceso de conformación de los foros, tampoco la hay respecto de su funcionamiento. Por ejemplo, existen foros liderados por una sola persona o que son casi unipersonales; foros que se manejan en su conducción de una manera colegiada o donde la conducción es compartida por más de dos personas. Hay foros que funcionan de manera centralizada en un lugar determinado y foros que actúan descentralizadamente, promoviendo reuniones en lugares diferentes como 
modo de cubrir toda la espacialidad que abarca la jurisdicción del foro.

Si bien no hemos ahondado en la investigación sobre las causas de esta diversidad, una hipótesis plausible, y que coincide con los datos obtenidos hasta el momento, es que un determinante fundamental de la misma es la desigual disponibilidad de capital social ${ }^{10}$ en los diferentes territorios. Así, donde existe una mayor densidad organizacional y las instituciones comunitarias son más fuertes y arraigadas, predomina un estilo de liderazgo y de conducción menos personalizado.

Desde la perspectiva de la composición social, los foros también muestran una importante diversidad asociada sin duda a la expresión territorial de las desigualdades sociales. En efecto, hay foros que en su conformación muestran un predominio de profesionales y personas dedicadas a la actividad comercial, en tanto en otros participan mayoritariamente personas asalariadas o incluso personas desempleadas. Donde sí se expresa un rasgo compartido - o los foros muestran cierta homogeneidad - es en la composición etaria: la mayoría de las personas que participan de los foros son adultos de mediana edad, siendo notable la ausencia de jóvenes.

Finalmente, respecto del tipo de organizaciones comunitarias que participan de los espacios forales, se observa una gran heterogeneidad institucional: asociaciones de comerciantes, clubes barriales, cooperadoras escolares, comedores comunitarios, asociaciones comunitarias que realizan tareas asistenciales, etc. Un rasgo común a todos los foros es la ausencia de organizaciones reivindicativas, como los movimientos de desocupados o de derechos humanos.

\section{La participación en los foros: identidad, prácticas y conflictos}

Un punto de partida para analizar la participación, análisis que obviamente no pretendemos agotar con este artículo, es como se auto-identifican los foristas. Es común en las entrevistas o en las reuniones de los foros escuchar "...los que estamos acá somos todos vecinos", “...los vecinos queremos...”, “...como dice el vecino...", etc.

En efecto, la categoría con la cual se nombran los foristas a sí mismos es la de vecinos. Los foristas de City Bell, al preguntársele por los orígenes del foro en dicha localidad, nos dijeron: "nosotros nos conocíamos porque somos vecinos, nada más" y "lo hacemos [trabajar en el foro] por vocación de vecinos".

El vecino que participa en el foro lo hace para mejorar su barrio y, como sostuvo la presidenta de uno de los foros del casco urbano, 'trabajar para los vecinos'. Así, los vecinos son sujeto y objeto de participación. Al respecto, un integrante del foro del barrio periférico de Altos de San Lorenzo señaló: “el objetivo del foro es que el vecino logre ir a la comisaría a hacer la denuncia, sin ningún temor, ese es el objetivo, pero para eso hay que trabajar muchísimo entre los vecinos para lograr sacar esos miedos."

$\mathrm{Si}$ se escudriña un poco esta forma de identificación, es posible encontrar la categoría moral del 'buen vecino', antes que una noción que señale a quienes habitan un espacio físico común, 'el barrio' . Por lo mismo, no todos los residentes de un barrio son considerados vecinos y el criterio de residencia, si bien necesario, resulta insuficiente: ser vecino remite a dimensiones morales y de reconocimiento. "Por suerte en el ministerio tienen eso [en cuenta]: si es reconocido como vecino eso se considera y puede tener voz y voto, aunque no tenga una institución, eso está bien", nos decía la mencionada presidenta de un foro céntrico de la ciudad, dejándonos entrever la significación implícita en ser considerado vecino.

Esa forma de nombrarse es interesante también porque en principio los foros, como fue dicho antes, son espacios que se constituyen a partir de representantes de organizaciones barriales, sin embargo la noción de vecino licua la idea misma de la representación. Así, quienes participan en los foros lo hacen antes que como representantes de alguna organización con un peculiar trabajo barrial o comunitario, como vecinos, categoría que en el discurso adquiere un carácter casi virginal e inmaculado. Lo que por un lado parece recrear el ágora de la polis griega - introduciendo un mecanismo de funcionamiento de democracia directa - pero, por el otro, inhibe la recuperación del capital social que pueden portar las organizaciones comunitarias.

A esta categoría identificatoria se lo oponen los 'otros': por un lado el delincuente y por el otro el político. El delincuente ha sido arrojado a ese lugar (el delito), bien por no haber logrado una trayectoria que lo integre socialmente, basada en el trabajo o en la educación, o bien porque no comparte los 'códigos morales' de la sociedad ${ }^{11}$. El político, en cambio, es quien no hace nada o lo que hace lo hace en miras de un rédito personal, como acumular poder para sí o '...llevar agua para su molino'.

Se observan en este punto varios desplazamientos significativos en la relación con la política y los políticos. Un forista de Altos de San Lorenzo señaló: "Yo estuve militando políticamente en muchas oportunidades, pero nunca mezclé los tantos y acá [por el foro] han venido de todos los ámbitos. Yo soy peronista de toda la vida, él [se refiere a otro integrante del foro] es radical, pero acá eso no tiene nada que ver, somos vecinos". Así, a diferencia de las identificaciones políticas, la categoría vecino parece no admitir ni heterogeneidad ni fisuras, como aquellas 
que podrían asignarse a la existencia de interés en conflicto o a diferentes visiones del mundo social. Por el contrario, es una noción homogénea que parece expulsar de sí a la política, o ir más allá (superar) las diferencias políticas, al menos las partidarias.

Es claro el esfuerzo reflexivo de los foristas por 'desmarcarse' de la política partidaria. "Tratamos de no hacerlo [las reuniones del foro] en lugares partidarios", nos contaba un forista del centro. "El foro es independiente de lo partidario, nosotros hacemos la política de seguridad para nosotros mismos", sostuvo el presidente del foro de un barrio periférico en una reunión de evaluación que tuvimos la posibilidad de observar, en la que estaban presentes los integrantes del foro, el comisario, el delegado municipal y muchos vecinos. Este esfuerzo por desdesmarcarse de las categorías propias de la política partidaria es un modo de diferenciarse de los políticos y a la vez (se espera, no siempre se logra) es una forma de conseguir mayor participación por parte de los vecinos. Una forista nos contaba que entre los obstáculos para la consolidación de los foros "está el descreimiento de los vecinos que miran atrás de eso [convocar a la participación en los foros] algún objetivo político". Desmarcarse de tal tipo de objetivos es, desde la perspectiva de los foristas, una condición necesaria para obtener el apoyo y la participación de los demás vecinos.

Una forista del barrio de Los Hornos lo sostuvo con total claridad, "es importante recalcarlo: que el foro no cobra, que es una política social y no partidaria". Se evidencia aquí el desplazamiento central que ha señalado Frederic (2005) en su trabajo sugerentemente titulado Buenos vecinos, malos políticos: desplazamiento en los barrios de lo político partidario a la militancia social.

También es necesario remarcar que son los "vecinos" quienes sufren la inseguridad y la falta de accionar de la justicia, de la policía o de los funcionarios. En ese sentido, la noción primitiva de vecino alude a quien se encuentra desprotegido frente al aumento de la inseguridad, que siempre se refiere a delitos contra las personas o contra la propiedad, dejándose de lado otras formas de inseguridad como las referidas a la violencia familiar - que pese a ser estadísticamente una de las agresiones más denunciadas, casi nunca es nombrada como delito o tematizada como hecho de violencia por los foristas - o las que tienen que ver con la falta de empleo o el acceso a bienes sociales, es decir la inseguridad social ${ }^{12}$.
En cuanto a los conflictos o tensiones que recorren la participación comunitaria, el más mencionado es el que opone a los foros con el poder gubernamental local. Según los foristas, desde el poder gubernamental local se han desplegado un conjunto de estrategias tendientes a quebrar el espacio foral, a desconocerlo o a cooptarlo.

Respecto de esta cuestión, los foristas entienden que el poder gubernamental local observa a los foros como un espacio que puede competirle políticamente o que teme que se constituya en una amenaza para el control que aquel ejerce a nivel territorial. Así, la Secretaria de uno de los foros de la periferia nos decía "...el municipio no quiere que los foros funcionen...", y continuaba “...ese pesimista que va y tira abajo la reunión, es solamente cuestión de acer-

carse a él y preguntarle de donde viene y uno enseguida, como en una línea, en dos segundos, sabe de donde viene la mano (refiriéndose de ese modo a la municipalidad)".

Es justamente en el marco de esa estrategia que los foristas ubican acciones del municipio como la conformación de la Comisión de Seguridad Ciudadana o la instalación de casetas para los policías. Es decir como dispositivos tendientes a quitar protagonismo a los foros, además de ser diseñados y ejecutados sin la partición de los mismos.

Si bien este conflicto parece indicar una tensión entre ciertas prácticas que contribuyen a una mayor democratización de las políticas públicas y el monopolio de las mismas que quiere reservarse el poder político local, los foristas no extraen, por el momento, todas las conclusiones del caso. Es decir, como se verá más adelante, la posible potencialidad de la participación comunitaria se encuentra inhibida por el tipo de prácticas que se llevan adelante en el espacio foral.

En cuanto a las prácticas de participación, el punto de entrada al análisis de la cuestión elegida para este artículo es el de centrarnos en el tipo de acciones desarrolladas por los foros.

Salvo en uno de los foros que viene desplegando acciones de prevención social del delito, fundamentalmente en temas de violencia familiar como capacitaciones, charlas, reuniones - inclusive generó un ámbito para acompañar a víctimas de maltrato familiar -, y que es uno de los más antiguos de La Plata, el resto han centrado sus actividades en cuestiones referidas al accionar policial.

Respecto a ese punto, es posible mencionar iniciativas como: propuestas para el reordenamiento de las 
cuadrículas de las seccionales policiales, establecimiento de mecanismos de control vecinal sobre el patrullaje policial, demandas para una mayor integración del accionar policial entre comisarías que limitan jurisdiccionalmente, pedidos para la creación de nuevas seccionales policiales o destacamentos y reclamos para una mayor presencia policial en las calles.

También resulta común que los foros funcionen como espacios de mediación entre los vecinos que sufren algún delito y las autoridades policiales. Asimismo, los foros promueven reuniones periódicas entre los vecinos y la policía de la jurisdicción para que las autoridades de esta última escuchen las demandas vecinales y expliquen a los vecinos sus planes en materia de seguridad.

De la apretada descripción realizada de las acciones de los foros, se puede señalar que los mismos no hacen uso de todas las posibilidades que brinda la Ley de Seguridad Pública y la política promovida oficialmente por el Ministerio de Seguridad.

En efecto, la prevención social y situacional del delito no es abordada de manera sistemática por la mayoría de los foros. Más bien, como se vio, estos se centran en el accionar represivo del Estado. A su vez, más que un espacio para cogestionar con el Estado la política de seguridad, los foros funcionan como ámbito de amplificación de las demandas barriales y como lugar de mediación entre los vecinos y la policía.

Respecto de esta última cuestión - referidas a demandas de mayor presencia punitiva del Estado -, en las entrevistas y observaciones hemos podido recoger frases, como "...esto es tierra de nadie"; “...la policía no es la culpable, si el policía hace lo echan por que hace, si no hace lo echan por que no hace..."; "otro problema es el de los menores, si hacen algo no se los puede tocar porque los protegen los Jueces."

Es necesario seguir explorando el estudio de los foros para poder extraer conclusiones más firmes sobre el hiato entre las potencialidades que parece encerrar el dispositivo institucional para la participación comunitaria en seguridad en la provincia de Buenos Aires y la participación efectiva. Sin embargo, una primera aproximación nos permite señalar la significación que tendría la cultura política ${ }^{13}$ para poder explicar esa brecha.

En esa dirección, y pese a que los foristas destacan la significación de los foros como espacios de participación - al respecto el Presidente del foro de Altos de San Lorenzo sostuvo: "los foros son instrumentos para controlar y para poder forzar decisiones", y la Secretaria del mismo foro argumentaba en la entrevista: "el foro es una herramienta valiosa, que al tener una ley que lo sustenta, va más allá de todo partidismo", podríamos afirmar que en ellos se ejerce una ciudadanía limitada, predominando una modalidad delegativa ${ }^{14}$. Es decir, predomina un ejercicio de la ciudadanía que tiende a implicarse poco en la cogestión de la política de seguridad y que centra su accionar en demandar sobre los poderes públicos, antes que imaginar formas de participación más activas que la lleven a formar parte de la toma de decisiones respecto de la seguridad ciudadana.

De todas formas, se podría argüir que los foros están comenzando de manera embrionaria, a partir de ciertas prácticas de responsabilización vertical de las autoridades policiales y ministeriales, un ejercicio de accountability que puede rematar en el ensanchamiento de los límites actuales de la participación y en el ejercicio de una ciudadanía ${ }^{15}$ más amplia.

\section{Conclusiones}

Al comienzo de este trabajo aludíamos al debate que ha generado la apelación a la participación de la sociedad civil en materia de políticas públicas y señalábamos la necesidad de enfocar la cuestión desde estudios empíricos, antes que desde posiciones abstractas y apriorísticas, sobre todo si lo que se quiere saber son los alcances y las limitaciones específicas de la participación.

Es más, consideramos que no hay que rehuir aquel debate sino enriquecerlo a partir de estudios concretos sobre los dispositivos institucionales diseñados para la participación y la investigación sobre las representaciones sociales y prácticas efectivas de participación de la sociedad civil.

En este artículo nos centramos específicamente en el segundo de los aspectos. En ese sentido nos parece importante señalar como conclusión general que la participación no opera en el vacío social sino que se encuentra imbricada y condicionada por las relaciones sociales más generales de una sociedad y que no es independiente del universo de significaciones que sobre el Estado y lo público portan los sujetos.

Así sostenemos, luego de nuestro análisis, que uno de los límites significativos que tiene la actual experiencia de participación comunitaria en materia de políticas de seguridad de la provincia de Buenos Aires, al menos en el municipio de La Plata, es el peculiar complejo de orientaciones valorativas que guían las prácticas de los sujetos, y que como tal no es autónomo de las tradiciones hegemónicas en que se ha expresado la participación, la cultura política y el ejercicio de la ciudadanía en nuestro país.

Son a nuestro entender esas orientaciones valorativas y esas tradiciones, junto a otras cuestiones no menos significativas, como la manera en que es ejercido el poder político, las que condicionan una participación y ciudadanía limitada. Aquellas se expresan tanto en la apelación a la noción 'despolitizada' de vecino como en las 
prácticas efectivas de participación centradas fundamentalmente en las demandas hacia el Estado y en la modesta implicación en el desarrollo de una agenda más amplia sobre la seguridad pública y en el despliegue de una cogestión más activa en la política pública de seguridad.

Sin embargo, pese al arraigo de las orientaciones valorativas y el peso de las tradiciones, también observamos el desenvolmiento de prácticas que pueden ensanchar, al menos en el ámbito de los foros, el ejercicio de la ciudadanía. Eso dependerá, en buena medida, del aprendizaje de los sujetos y de la apropiación efectiva del alcance de esa política pública.

\section{Referencias}

CASTEL, R. La inseguridad social ¿Qué es estar protegido? Buenos Aires: Manantial, 2004.

CHINCHILLA, L.; RICO, J. La prevención comunitaria del delito. Perspectivas para América Latina. Centro para la Administración de Justicia. Universidad Internacional de Florida. Florida, 1997.

FREDERIC, S. Buenos vecinos, malos políticos. Moralidad y política en el Gran Buenos Aires. Buenos Aires: Prometeo, 2005.

LECHNER, N. Tres formas de coordinación social. Revista de la CEPAL, Santiago de Chile, n. 61, abril, 1997.

MAGARIÑOS DE MORENTIN, J. Los fundamentos lógicos de la semiótica y su práctica. Buenos Aires: Edicial, 1996.

MARTEAU, J. F. Azul casi negro: la gestión policial en Buenos Aires. Notas para una política policial democrática. En BRICEÑO-LEÓN, R. (Comp.). Violencia, sociedad y justicia en América Latina. Buenos Aires: CLACSO, 2002.

MINISTERIO DE SEGURIDAD. Cuadernos del Foro N. 1. Subsecretaría de Participación Comunitaria. Gobierno de la Provincia de Buenos Aires, La Plata, 2004.

O’ DONNELL, G. Estado, democratización y ciudadanía. Revista Nueva Sociedad, Caracas: Editorial Nueva Sociedad, n. 128, 1993.

Otra institucionalización. Revista Agora, Buenos Aires, n. 5, p. 5-28, 1996.

ROBOTNIKOF, N. La caracterización de la sociedad civil en la perspectiva del BID y del BM. Revista Perfiles Latinoamericanos, FLACSO. México, v. 8, n.15, p. 29-31, 1999.

SAIN, M. Seguridad, democracia y reforma del sistema policial en la Argentina. Buenos Aires: FCE, 2002.
SARMIENTO, J. Ensanchando los límites: la sociedad civil y las políticas públicas para el desarrollo sustentable. En: Movimientos sociales, representación política y transformaciones sociales: desafíos a la investigación y a la intervención en Trabajo Social. Escuela Superior de Trabajo Social-UNLP, La Plata, 2002. 1 CD-ROM.

. El problema de la inseguridad. Documento Interno. Núcleo de Estudios Socioculturales. Escuela Superior de Trabajo Social. La Plata, UNLP, 2005.

WOLFE, A. Três caminhos para o desenvolvimento: mercado, Estado e sociedade civil. Desenvolvimento, Cooperação Internacional e as ONGs. Rio de Janeiro, IBASE, PNUD, 1992.

\section{Notas}

1 Versión revisada de la ponencia presentada a las VI Jornadas de Investigación en Trabajo Social y III Jornadas de Extensión Universitaria La producción de conocimientos en ciencias sociales y su aporte a la construcción de un proyecto de sociedad. Facultad de Trabajo Social. Universidad Nacional de La Plata. La Plata, 14 y 15 de septiembre de 2006.

2 Sobre las diferentes posiciones en la discusión acerca de la participación de la sociedad civil en materia de políticas públicas, puede consultarse: Lechner (1997); Rabotnikof (1999); Sarmiento(2002); Wolfe(1992).

3 El estudio de los foros de seguridad se inscribe en el marco de la investigación de la política de seguridad de la Provincia de Buenos Aires, que a su vez forma parte de un proyecto más amplio denominado Seguridad/Inseguridad y Violencia en la Provincia de Buenos Aires. Un estudio de las representaciones sociales y de las politicas de seguridad. Directora: Lic. Virginia Ceirano. Núcleo de Estudios Socioculturales, Facultad de Trabajo Social, Universidad Nacional de La Plata. Acreditado por el Programa de Incentivos a la Investigación (SPU-UNLP).

4 El proceso de reforma puede leerse en Sain (2002).

5 Ambas leyes están disponibles en la web. La ley de Seguridad Pública 12.154 se encuentra en el sitio del gobierno de la provincia de Buenos Aires (http://www.gob.gba.gov.ar/ Legislación/Legislación/I-12154.htlm) y la ley Organización de las Policías de la Provincia de Buenos Aires 12.155 en el sitio del Ministerio de Seguridad de la provincia de Buenos Aires (http://www.mseg.gba.gov.ar/Leyes).

6 Una caracterización del sistema de seguridad provincial y su crisis puede verse en Sain (2002). 
7 Ver al respecto Marteau (2002), Chinchilla y Rico (1997), Sarmiento(2005).

8 Más adelante se describe cómo se integran los foros vecinales, que son el objeto de nuestro trabajo en el momento actual de la investigación.

9 Carlos Arslanian ya había sido Ministro de Seguridad entre abril de 1998 y agosto de 1999. Como fue ya expresado, la reforma del sistema de seguridad de la Provincia de Buenos Aires y la apelación a la participación comunitaria en la política de seguridad provincial fue impulsada por la Intervención Civil de la Policía Bonaerense, bajolagestión de LuisLugones, y continuada bajo la primera gestión del Ministro Arslanian.

10 Si bien hay diversas definiciones del capital social, aquí la usamos en el sentido de la densidad organizacional de la comunidad y su historia en materia de participación social y políica.

11 En efecto, en los relatos de los foristas las explicaciones acerca de las causas de la inseguridad y el delito se colocan en un continuo cuyos polos extremos son, por un lado, las argumentaciones que enfatizan dimensiones socioeconómicas, como el desempleo y la pobreza, y por otro lado, las argumentaciones de tipo culturalista, que centran la explicación en lafalta de educación, problemas morales, etc. Nos es extraño que un mismo actor alterne entre ambas posiciones.

12 Sobre la inseguridad social ver Castel (2004).

13 Entendida de manera amplia y referida a los valores dominantes sobre lo público, así como las tradiciones de participación e involucramiento en la esfera público-política presentes en la sociedad.

14 Sobre laidea de delegación verO'Donnell $(1993,1996)$.

15 Usamos la noción de ciudadanía de una forma que trasciende la idea estrecha de una miríada de derechos y obligaciones, es decir la entendemos como un conjunto de prácticas sociales que refieren a la implicación en lo público y el control sobre los actos de gobierno.

\section{Julio Sarmiento}

Politólogo

Candidato a Doctor en el Estudio de las Sociedades

Latinoamericanas

Profesor Adjunto de Sociología de la Facultad de

Trabajo Social, Universidad Nacional de La Plata.

\section{Claudia Tello}

Antropóloga

Profesora Titular de Antropología Social II de la

Facultad de Trabajo Social,

Universidad Nacional de La Plata

\section{Ramiro Segura}

Antropólogo

Cursante del Doctorado en Ciencias Sociales de la

Universidad Nacional de General Sarmiento y el

Instituto de Desarrollo Económico y Social.

Becario Centro de Investigaciones Etnográficas,

Universidad Nacional de San Martín.

Docente de Antropología de la Facultad de Trabajo

Social, Universidad Nacional de La Plata

Universidad Nacional de La Plata

Facultad de Trabajo Social

Calle 9 esq. 63

CP 1900

La Plata, Buenos Aires, Argentina. 